\title{
FENÓIS TOTAIS E ATIVIDADE ANTIOXIDANTE DE CINCO PLANTAS MEDICINAIS
}

Cleyton Marcos de M. Sousa, Hilris Rocha e Silva, Gerardo Magela Vieira-Jr., Mariane Cruz C. Ayres, Charllyton Luis S. da Costa, Delton Sérvulo Araújo, Luis Carlos D. Cavalcante, Elcio Daniel S. Barros, Paulo Breitner de M. Araújo, Marcela S. Brandão e Mariana H. Chaves*

Departamento de Química, Universidade Federal do Piauí, 64049-550 Teresina - PI, Brasil

Recebido em 19/1/06; aceito em 23/6/06; publicado na web em 19/1/07

\begin{abstract}
TOTAL PHENOLICS AND ANTIOXIDANT ACTIVITY OF FIVE MEDICINAL PLANTS. This paper describes total phenolics content and antioxidant activity in the ethanolic extract of leaves, bark and roots of five medicinal plants: Terminalia brasiliensis Camb., Terminalia fagifolia Mart. \& Zucc., Copernicia cerifera (Miller) H.E. Moore, Cenostigma macrophyllum Tul. var. acuminata Teles Freire and Qualea grandiflora Mart. The total phenolics content of the plant extracts, determined by the Folin-Ciocalteu method, varied from $250.0 \pm 8,2$ to $763,63 \pm 13.03 \mathrm{mg}$ of gallic acid equivalent/g dry EtOH extract. The antioxidant activity of extracts was evaluated using the 2,2-diphenyl-1-picrylhydrazyl (DPPH) assay system. Extract of bark from T. brasiliensis, the most active, with an $\mathrm{EC}_{50}$ value of $27.59 \pm 0.82 \mu \mathrm{g} / \mathrm{mL}$, was comparable to rutin $\left(\mathrm{EC}_{50}=27.80 \pm 1.38\right)$ and gallic acid $\left(\mathrm{EC}_{50}=24.27 \pm 0.31\right)$, used as positive controls. The relationship between total phenolic content and antioxidant activity was positive and significant for $T$. brasiliensis, C. macrophyllum and C. cerifera.
\end{abstract}

Keywords: total phenolics; antioxidant activity; medicinal plants.

\section{INTRODUÇÃO}

Nos últimos anos, uma quantidade substancial de evidências tem indicado o papel chave dos radicais livres e outros oxidantes como grandes responsáveis pelo envelhecimento e pelas doenças degenerativas associadas ao envelhecimento, como câncer, doenças cardiovasculares, catarata, declínio do sistema imune e disfunções cerebrais ${ }^{1}$.

Espécies reativas de oxigênio (EROs), tais como radical hidroxila $\left({ }^{\circ} \mathrm{OH}\right)$, ânion radical superóxido $\left(\mathrm{O}_{2}^{--}\right)$e hidroperoxila ( $\left.\left.\mathrm{ROO}\right)^{*}\right)$, causam danos ao DNA ou podem oxidar lipídios e proteínas. Os EROs atacam as cadeias de ácidos graxos poliinsaturados dos fosfolipídios e do colesterol, abstraindo um hidrogênio do grupo metileno bis-alílico, iniciando assim o processo de peroxidação lipídica nas membranas celulares. Os radicais de carbono formados podem reagir com oxigênio originando radicais peroxila, que por sua vez podem atacar novas cadeias de ácidos graxos poliinsaturados, propagando a reação. O resultado deste processo é a oxidação de várias moléculas de ácidos graxos ${ }^{2,3}$.

Os hidroperóxidos formados na peroxidação lipídica têm vida curta e, quando reagem com metais, formam aldeídos (isto é, malonaldeído, acroleína, crotonaldeído) e epóxidos, os quais são reativos e causam danos de novo ao $\mathrm{DNA}^{2}$.

A produção de radicais livres é controlada nos seres vivos por diversos compostos antioxidantes, os quais podem ter origem endógena (por ex., superóxido dismutase), ou serem provenientes da dieta alimentar e outras fontes. Destas últimas destacam-se tocoferóis (vitamina E), ácido ascórbico (vitamina C), polifenóis, selênio e carotenóides $^{2,3}$. Quando há limitação na disponibilidade de antioxidantes podem ocorrer lesões oxidativas de caráter cumulativo. Os antioxidantes são capazes de estabilizar ou desativar os radicais livres antes que ataquem os alvos biológicos nas células ${ }^{1}$.

A vitamina E é a designação dada a um grupo de compostos antioxidantes liposolúveis, entre os quais o $\alpha$-tocoferol é a forma mais ativa. É encontrada em lipoproteínas e membranas, atuando no bloqueio da reação em cadeia da peroxidação lipídica, através do seqües-

*e-mail:mariana@ufpi.br tro do radical peroxila. A vitamina $\mathrm{C}$ tem muitas funções fisiológicas, entre elas, o alto poder antioxidante de reciclar a vitamina $\mathrm{E}$ no processo de peroxidação lipídica das membranas e lipoproteínas ${ }^{2,3}$.

Os carotenos (CAR) protegem os lipídios dos danos peroxidativos inativando o oxigênio singleto, sem sofrer degradação, através da reação com os radicais peroxila, hidroxila e superóxido. A atividade antioxidante dos CAR é decorrente da habilidade de deslocalizar elétrons desemparelhados através da estrutura de ligações duplas conjugadas, sendo relatadas na literatura três propostas de mecanismos para a reação de radicais livres com $\mathrm{CAR}^{2}$.

De forma geral, denominam-se antioxidantes as substâncias que presentes em concentrações baixas, comparadas ao substrato oxidável, retardam significativamente ou inibem a oxidação do substrato. Os radicais formados a partir de antioxidantes não são reativos para propagar a reação em cadeia, sendo neutralizados por reação com outro radical, formando produtos estáveis ou podem ser reciclados por outro antioxidante $e^{1,2}$.

\section{Compostos fenólicos como antioxidantes}

Os compostos fenólicos de plantas enquadram-se em diversas categorias, como fenóis simples, ácidos fenólicos (derivados de ácidos benzóico e cinâmico), cumarinas, flavonóides, estilbenos, taninos condensados e hidrolisáveis, lignanas e ligninas ${ }^{4}$.

Dentre as diversas classes de substâncias antioxidantes de ocorrência natural, os compostos fenólicos têm recebido muita atenção nos últimos anos, sobretudo por inibirem a peroxidação lipídica e a lipooxigenase in vitro $^{3,5}$.

A atividade antioxidante de compostos fenólicos deve-se principalmente às suas propriedades redutoras e estrutura química. Estas características desempenham um papel importante na neutralização ou seqüestro de radicais livres e quelação de metais de transição, agindo tanto na etapa de iniciação como na propagação do processo oxidativo. Os intermediários formados pela ação de antioxidantes fenólicos são relativamente estáveis, devido à ressonância do anel aromático presente na estrutura destas substâncias ${ }^{3,5,6}$. 
Embora as evidências sejam claras sobre a ação in vitro dos fenóis e polifenóis com espécies reativas de oxigênio eles podem, em algumas circunstâncias, tal como o ascorbato e os carotenóides, mostrarem características pró-oxidantes ${ }^{2,3}$.

$\mathrm{Na}$ indústria alimentícia, a oxidação lipídica é inibida por seqüestradores de radicais livres. Os compostos mais utilizados com esta finalidade são o butil-hidroxi-anisol (BHA), butil-hidroxi-tolueno (BHT), terc-butil-hidroxi-quinona (TBHQ), tri-hidroxi-butil-fenona (THBP) e galato de propila (GP). Estudos têm demonstrado a possibilidade destes antioxidantes apresentarem alguns efeitos tóxicos. $\mathrm{O}$ galato de propila, por ex., quando em presença de peróxido de hidrogênio reage com íons ferrosos formando espécies reativas de oxigênio, as quais podem posteriormente atacar alvos biológicos ${ }^{3,5}$.

Em função dos possíveis problemas provocados pelo consumo de antioxidantes sintéticos, as pesquisas têm-se voltado no sentido de encontrar produtos naturais com atividade antioxidante, os quais permitirão substituir os sintéticos ou fazer associação entre eles.

\section{Determinação de fenóis e polifenóis}

A quantificação espectrométrica de compostos fenólicos é realizada por meio de uma variedade de técnicas, todavia, a que utiliza o reagente de Folin-Ciocalteu figura entre as mais extensivamente utilizadas $^{2,4,7,9,10}$. O reagente consiste de mistura dos ácidos fosfomolibídico e fosfotunguístico, no qual o molibdênio e o tungstênio encontram-se no estado de oxidação $6^{+}$porém, em presença de certos agentes redutores, como os compostos fenólicos, formam-se os chamados molibdênio azul e tungstênio azul, nos quais a média do estado de oxidação dos metais está entre 5 e 6 e cuja coloração permite a determinação da concentração das substâncias redutoras, que não necessariamente precisam ter natureza fenólica ${ }^{4,11}$.

\section{Avaliação in vitro de atividade antioxidante}

Vários métodos são utilizados para determinar a atividade antioxidante em extratos e substâncias isoladas; um dos mais usados consiste em avaliar a atividade seqüestradora do radical livre 2,2difenil-1-picril-hidrazila - DPPH', de coloração púrpura que absorve a $515 \mathrm{~nm}^{10}$. Por ação de um antioxidante $(\mathrm{AH})$ ou uma espécie radicalar $\left(\mathrm{R}^{*}\right)$, o DPPH' é reduzido formando difenil-picril-hidrazina, de coloração amarela, com conseqüente desaparecimento da absorção, podendo a mesma ser monitorada pelo decréscimo da absorbância. A partir dos resultados obtidos determina-se a porcentagem de atividade antioxidante ou seqüestradora de radicais livres e/ou a porcentagem de DPPH' remanescente no meio reacional ${ }^{12,13}$.

A porcentagem de atividade antioxidante $(\% \mathrm{AA})$ corresponde à quantidade de DDPH consumida pelo antioxidante, sendo que a quantidade de antioxidante necessária para decrescer a concentração inicial de DPPH em 50\% é denominada concentração eficiente $\left(\mathrm{CE}_{50}\right)$, também chamada de concentração inibitória $\left(\mathrm{CI}_{50}\right)$. Quanto maior o consumo de DPPH por uma amostra, menor será a sua $\mathrm{CE}_{50}$ e maior a sua atividade antioxidante.

\section{Plantas medicinais do semi-árido piauiense}

Como parte de nossos estudos sobre a investigação da composição química e ação farmacológica de plantas medicinais do semiárido piauiense e considerando a importância de compostos fenólicos como antioxidantes, o presente trabalho teve como objetivo determinar os fenóis totais, pelo método Folin-Ciocalteu, e avaliar a atividade antioxidante, pelo ensaio do DPPH, do extrato etanólico de cinco plantas medicinais: Terminalia brasiliensis Camb., Terminalia fagifolia Mart. et Zucc., Cenostigma macrophyllum Tul. var. acuminata Teles Freire, Qualea grandiflora Mart. e Copernicia prunifera (Miller) H. E. Moore.

T. brasiliensis (Combretaceae) é conhecida como amêndoa-brava, cerne-amarelo, capitão-do-campo, catinga-de-porco, mussambé, entre outros. Sua utilização é amplamente difundida na medicina popular no tratamento de "barriga inchada" e "disenteria"; produz matéria tintorial e a casca é escura e adequada para uso em curtume $^{14}$. O estudo químico realizado com a fração hexânica da partição do extrato etanólico das folhas desta espécie resultou no isolamento de vários triterpenóides pentacíclicos e na fração hidroalcoólica do mesmo extrato foi confirmada a presença de taninos gálicos ${ }^{15,16}$.

T. fagifolia é uma Combretaceae conhecida comumente como capitão, capitão-do-mato, mirindiba e pau-de-bicho. Trata-se de uma espécie melífera e ornamental, seus frutos são utilizados no artesanato e a madeira pode ser empregada na construção civil. Na medicina popular, a casca do caule é usada no combate a aftas e tumores ${ }^{17}$.

C. macrophyllum (Leguminosae-Caesalpinioideae) é conhecida popularmente como caneleiro, canela de velho, entre outros. Em levantamento etnobotânico realizado na região do semi-árido piauiense foi constatado que as folhas, cascas do caule e flores desta espécie são usadas no tratamento de doenças estomacais e intestinais. O estudo químico-farmacológico realizado resultou no isolamento de triterpenóides pentacíclicos e bisflavonas e na comprovação de ações antiinflamatória, antinociceptiva, antiulcerogênica e antibacteriana no extrato etanólico das folhas ${ }^{18}$.

Q. grandiflora é uma Vochysiaceae, típica do cerrado, conhecida como pau-terra-da-folha-grande, pau-terra-do-cerrado e ariavá. A infusão dos frutos é usada no tratamento de asma $^{14}$ e a infusão das cascas, para limpeza externa de úlceras e feridas e, também, contra inflamações ${ }^{17}$.

C. prunifera (Arecaceae) é conhecida comumente como carnaúba. As folhas desta espécie acumulam uma cera constituída basicamente de ésteres, álcoois e ácidos graxos de massa molecular alta. A cera é utilizada na fabricação de cosméticos e produtos de limpeza, filmes plásticos e fotográficos. É usada ainda, na composição de revestimentos, impermeabilizantes, lubrificantes, vernizes papel-carbono, dentre outros ${ }^{19}$. A raiz da carnaúba é popularmente utilizada na forma de elixir, para tratamento de sífilis e afecções cutâneas ${ }^{20}$.

\section{PARTE EXPERIMENTAL}

\section{Procedimentos experimentais gerais}

Todos os solventes e reagentes usados eram analiticamente puros. O reagente Folin-Ciocalteu foi adquirido da Merck, o radical DPPH (2,2-difenil-1-picril-hidrazila) da Aldrich Co, o ácido gálico da Vetec e a rutina da PVP Sociedade Anônima, Parnaíba-PI. As medidas de absorção foram feitas usando espectrofotômetro UVVis Hytachi U-3000.

\section{Material vegetal}

Cascas e folhas de T. brasiliensis (TEPB 10340) e folhas de $T$. fagifolia (TEPB 18061) foram coletadas no município de Nazaré do Piauí em agosto e setembro de 2002, respectivamente, e folhas de Q. grandiflora (TEPB 10091) no município de Demerval LobãoPI em abril de 2002. Folhas de C. macrophyllum (TEPB 10374) foram coletadas em julho de 2004 na sede do Sindicato dos Trabalhadores da Universidade Federal do Piauí (SINTUFPI), Teresina PI e raízes de carnaúba no município de Campo Maior - PI, em janeiro de 2004. Todas as exsicatas encontram-se depositadas no Herbário Graziela Barroso da UFPI. 


\section{Preparação dos extratos}

O material vegetal foi seco à temperatura ambiente e moído em moinho de facas. Os extratos foram preparados por maceração com etanol à temperatura ambiente por quatro vezes consecutivas e cada extração tinha a duração de 4 dias. Os extratos foram reunidos, concentrados em evaporador rotativo e liofilizados em liofilizador E-C MicroModulyo acoplado à bomba de vácuo valuPump VLP80 Savant. $\mathrm{O}$ rendimento dos extratos foi calculado pela expressão: Rendimento $(\%)=($ massa do extrato/massa do material vegetal $) \times 100$.

\section{Determinação de fenóis totais}

A determinação do teor de fenóis totais presentes nas amostras de extrato etanólico das espécies estudadas foi feita por meio de espectroscopia na região do visível utilizando o método de Folin-Ciocalteu com modificações $^{7}$. O extrato etanólico $(100 \mathrm{mg})$ foi dissolvido em metanol, transferido quantitativamente para um balão volumétrico de $100 \mathrm{~mL}$ e o volume final foi completado com metanol. Uma alíquota de 7,5 $\mathrm{mL}$ desta solução foi transferida para um balão volumétrico de $50 \mathrm{~mL}$; esta segunda solução teve seu volume acertado novamente com metanol. Uma alíquota de $100 \mu \mathrm{L}$ desta última solução foi agitada com $500 \mu \mathrm{L}$ do reagente de FolinCiocalteu e $6 \mathrm{~mL}$ de água destilada por $1 \mathrm{~min}$; passado este tempo $2 \mathrm{~mL}$ de $\mathrm{Na}_{2} \mathrm{CO}_{3}$ a $15 \%$ foram adicionados à mistura e agitada por $30 \mathrm{~s}$. Finalmente, a solução teve seu volume acertado para $10 \mathrm{~mL}$ com água destilada. Após 2 h, a absorbância das amostras foi medida a $750 \mathrm{~nm}$ utilizandose cubetas de vidro, tendo como "branco" o metanol e todos os reagentes, menos o extrato. O teor de fenóis totais (FT) foi determinado por interpolação da absorbância das amostras contra uma curva de calibração construída com padrões de ácido gálico (10 a $350 \mu \mathrm{g} / \mathrm{mL})$ e expressos como mg de EAG (equivalentes de acido gálico) por g de extrato. A Equação da curva de calibração do ácido gálico foi $C=809,0200 A+5,0827$, onde $C$ é a concentração do ácido gálico, $A$ é a absorbância a $750 \mathrm{~nm}$ e o coeficiente de correlação $R=0,999$. Todas as análises foram realizadas em triplicata.

\section{Análise qualitativa da atividade antioxidante}

Os extratos foram analisados por CCD usando rutina como padrão positivo de comparação. As placas foram eluídas em $\mathrm{CHCl}_{3} /$ $\mathrm{MeOH}$ (9:1) e $\mathrm{CHCl}_{3} / \mathrm{MeOH} / \mathrm{H}_{2} \mathrm{O}$ (65:30:5) e, após secagem, foram nebulizadas com solução a $0,4 \mathrm{mmol} / \mathrm{L}$ do radical DPPH em $\mathrm{MeOH}^{21}$. As placas foram observadas até o aparecimento de manchas amarelas sob fundo de coloração púrpura, indicativo de possível atividade antioxidante.

\section{Análise quantitativa da atividade antioxidante}

A avaliação quantitativa da atividade antioxidante foi feita seguindo metodologia descrita na literatura, com pequenas modificações, monitorando-se o consumo do radical livre DPPH pelas amostras, através da medida do decréscimo da absorbância de soluções de diferentes concentrações ${ }^{12,13}$. Estas medidas foram feitas em espectrofotômetro UV-Vis no comprimento de onda $516 \mathrm{~nm}$, tendo como controle positivo rutina e ácido gálico.

\section{Construção da curva de calibração do DPPH}

Primeiramente, foram preparados $50 \mathrm{~mL}$ de solução estoque de DPPH em metanol na concentração de $40 \mu \mathrm{g} / \mathrm{mL}$, mantida sob refrigeração e protegida da luz. Foram feitas diluições de 35, 30, 25, $20,15,10,5$ e $1 \mu \mathrm{g} / \mathrm{mL}$. A curva de calibração foi construída a partir dos valores da absorbância a $515 \mathrm{~nm}$ de todas as soluções (1 a $40 \mu \mathrm{g} / \mathrm{mL}$ ), medidas em cubetas de vidro com percurso óptico de $1 \mathrm{~cm}$ e tendo como "branco" o metanol. As medidas de absorbância foram efetuadas em triplicata e em intervalos de 1 min entre cada leitura. A Equação da curva de calibração do DPPH foi $C=35,846 A$ - 0,230, onde $C$ corresponde à concentração de DPPH no meio, $A$ é a absorbância medida no comprimento de onda de $516 \mathrm{~nm}$ e o coeficiente de correlação $R=0,9997$.

\section{Leitura das medidas de absorbância nas amostras}

Soluções dos extratos EtOH $(500 \mu \mathrm{g} / \mathrm{mL})$ e dos controles positivos em metanol foram diluídas nas concentrações de 250, 200, 150, 100, 50 e $25 \mu \mathrm{g} / \mathrm{mL}$. As medidas das absorbâncias das misturas reacionais $(0,3 \mathrm{~mL}$ da solução da amostra ou do controle positivo e $2,7 \mathrm{~mL}$ da solução estoque de DPPH na concentração de 40 $\mu \mathrm{g} / \mathrm{mL}$ ) foram feitas a $515 \mathrm{~nm}$, no $1^{\circ}, 5^{\circ}$ e $10^{\circ} \mathrm{min}$, a cada $10 \mathrm{~min}$ até completar $1 \mathrm{~h}$. A mistura de metanol $(2,7 \mathrm{~mL})$ e solução metanólica do extrato $(0,3 \mathrm{~mL})$ foi utilizada como branco.

A partir da equação da curva de calibração e dos valores de absorbância no tempo de 30 min para cada concentração testada, foram determinados os percentuais de DPPH remanescentes $(\%$ $\mathrm{DPPH}_{\mathrm{REM}}$ ), conforme a Equação:

$\% \mathrm{DPPH}_{\mathrm{REM}}=[\mathrm{DPPH}]_{\mathrm{T}=\mathrm{t}} /[\mathrm{DPPH}]_{\mathrm{T}=0} \mathrm{x} 100$

onde $[\mathrm{DPPH}]_{\mathrm{T}=\mathrm{t}}$ corresponde à concentração de DPPH no meio, após a reação com o extrato e $[\mathrm{DPPH}]_{\mathrm{T}=0}$ é a concentração inicial de $\mathrm{DPPH}$, ou seja, $40 \mathrm{mg} / \mathrm{mL}(100 \mu \mathrm{mol} / \mathrm{mL})^{12,13,21}$.

A concentração eficiente, quantidade de antioxidante necessária para decrescer a concentração inicial de DPPH em $50 \%\left(\mathrm{CE}_{50}\right)$, foi determinada usando o programa Microcal Origin 7.5, a partir de uma curva exponencial de primeira ordem, obtida plotando-se na abscissa as concentrações da amostra $(\mu \mathrm{g} / \mathrm{mL})$ ou do controle positivo e na ordenada, a porcentagem de DPPH remanescente $\left(\% \mathrm{DPPH}_{\mathrm{REM}}\right)^{13}$.

Os valores de absorbância em todas as concentrações testadas, no tempo de $30 \mathrm{~min}$, foram também convertidos em porcentagem de atividade antioxidante (AA), determinada pela Equação:

$\% \mathrm{AA}=\left\{\left[\mathrm{Abs}_{\text {controle }}-\left(\mathrm{Abs}_{\text {amostra }}-\mathrm{Abs}_{\text {branco }}\right)\right] \times 100\right\} / \mathrm{Abs}_{\text {controle }}$

onde $\mathrm{Abs}_{\text {controle }}$ é a absorbância inicial da solução metanólica de

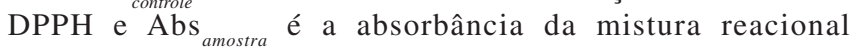
$(\mathrm{DPPH}+\mathrm{amostra})^{22,23}$.

\section{Análise estatística}

Os resultados apresentados neste estudo correspondem à média de três repetições $(n=3) \pm$ desvio padrão da média. Foram considerados estatisticamente diferentes os resultados de atividade antioxidante que apresentaram probabilidade de ocorrência da hipótese de nulidade menor que 5\% $(P<0,05)$ aplicando-se ANOVA, seguido de comparações múltiplas pelo teste de Tukey. Coeficientes de correlação foram determinados entre o conteúdo de fenóis totais e a concentração eficiente de cada extrato, $\mathrm{CE}_{50}$. Todas as análises foram realizadas usando o programa Microcal Origin 7.5.

\section{RESULTADOS E DISCUSSÃO}

A avaliação preliminar qualitativa dos extratos por CCD em gel de sílica, revelada com solução metanólica a $0,4 \mathrm{mmol} / \mathrm{L}$ do radical DPPH, sugeriu a existência de substâncias com atividade antioxidante, evidenciadas nas cromatoplacas pela presença de manchas amarelas sobre fundo púrpuro, resultantes da redução do radical DPPH. 
A quantidade de extrato das plantas testadas necessária para decrescer a concentração inicial de DPPH em 50\%, $\mathrm{CE}_{50}$ (Tabela 1), variou de 27,59 $\pm 0,82$ a $111,14 \pm 12,48 \mu \mathrm{g} / \mathrm{mL}$, sendo que o extrato EtOH de cascas de $T$. brasiliensis $\left(\mathrm{CE}_{50}=27,59 \pm 0,82\right)$ mostrou-se comparável aos controles positivos rutina $\left(\mathrm{CE}_{50}=27,80 \pm 1,38 \mu \mathrm{g}\right.$ / $\mathrm{mL})$ e ácido gálico $\left(\mathrm{CE}_{50}=24,27 \pm 0,31 \mu \mathrm{g} / \mathrm{mL}\right)$, enquanto o extrato EtOH da $C$. prunifera apresentou o maior valor $\left(\mathrm{CE}_{50}=111,14 \pm 12,48\right)$.

Os resultados da avaliação quantitativa da atividade antioxidante (\%AA) do extrato etanólico de $T$. brasiliensis (folha e casca), $T$. fagifolia (folha), C. macrophyllum (folha), Q. grandiflora (folha) e C. prunifera (raiz) e dos controles positivos, nas concentrações de 100,50 e $25 \mu \mathrm{g} / \mathrm{mL}$, determinada pelo ensaio do DPPH, estão apresentados na Figura 1, mostrando que todas as espécies têm atividade seqüestradora do radical DPPH, contudo o extrato de $C$. prunifera foi o menos ativo nas três concentrações. As demais amostras de extratos, na concentração de $100 \mu \mathrm{g} / \mathrm{mL}$, apresentaram atividade antioxidante superior a $60 \%$, atingindo um máximo de $91,36 \pm$ $0,55 \%$ para o extrato de casca de T. brasiliensis contra $94,84 \pm$ $0,44 \%$ do ácido gálico e $89,25 \pm 0,25 \%$ da rutina.

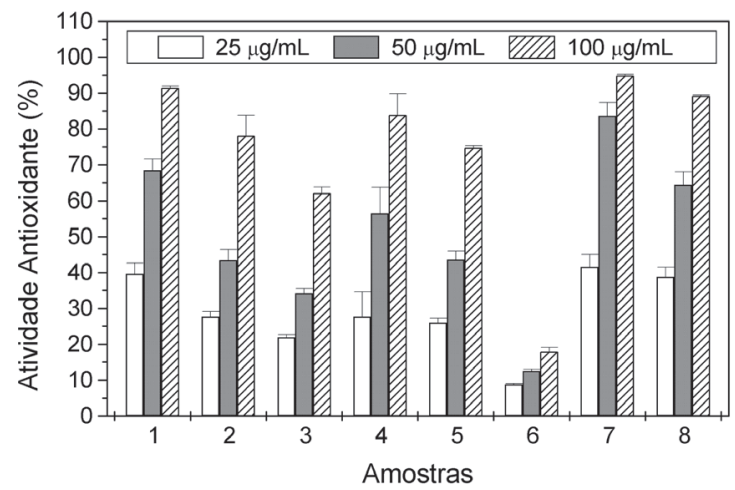

Figura 1. Porcentagem de atividade antioxidante do extrato etanólico de plantas medicinais do semi-árido piauiense e dos controles (tempo de reação com o DPPH: $30 \mathrm{~min}$ ). 1. T. brasiliensis (casca); 2. T. brasiliensis (folha); 3. C. macrophyllum (folha); 4. T. fagifolia (folha); 5. Q. grandiflora (folha); 6. C. prunifera (raiz); 7. ácido gálico; 8 . rutina

Levando-se em consideração a análise estatística dos dados de atividade antioxidante em todas as concentrações testadas $(25,50$, 100, 150, 200 e $250 \mu \mathrm{g} / \mathrm{mL}$ ), aplicando-se ANOVA e teste de Tukey, verificou-se que à exceção da $C$. prunifera, as demais espécies não apresentaram diferenças significativas $(P<0,05)$ no potencial como fontes de substâncias seqüestradoras de radicais livres, nem mesmo com relação aos controles positivos.

O comportamento cinético da reação do DPPH com cada extrato ou controle, na concentração de $100 \mu \mathrm{g} / \mathrm{mL}$, é mostrado na Figu- ra 2, através na curva de dose-resposta relativa ao decréscimo da porcentagem remanescente de DPPH $\left(\% \mathrm{DPPH}_{\mathrm{REM}}\right)$ em função do tempo (min). Observou-se que todas as amostras apresentaram cinética rápida, atingindo praticamente o máximo de consumo do DPPH no primeiro minuto, com uma porcentagem de DPPH remanescente menor que $50 \%$, exceto para o extrato da $C$. prunifera, que não mostrou aumento significativo do consumo de DPPH nem mesmo ao longo do tempo total de observação (60 min).

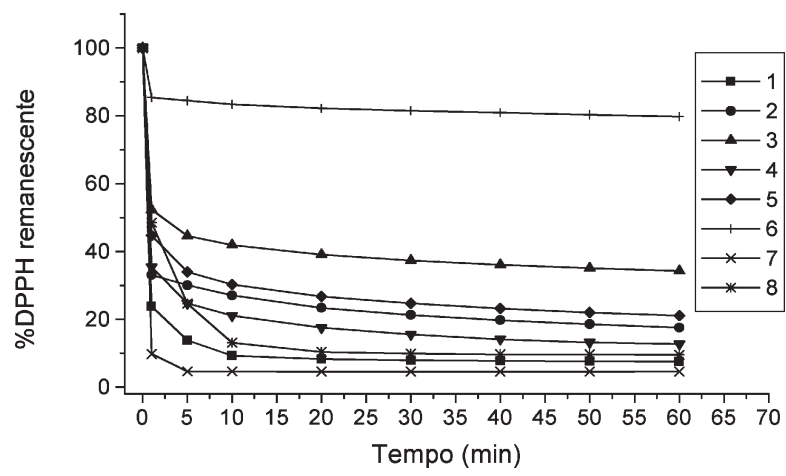

Figura 2. Comportamento cinético do extrato etanólico $(100 \mu \mathrm{g} / \mathrm{mL})$ frente aо DPPH. 1. T. brasiliensis (casca); 2. T. brasiliensis (folha); 3. C. macrophyllum (folha); 4. T. fagifolia (folha); 5. Q. grandiflora (folha); 6. C. prunifera (raiz); 7. ácido gálico; 8 . rutina

Os resultados obtidos na determinação dos fenóis totais (FT) pelo método Folin-Ciocalteu, expressos como equivalentes de ácido gálico (EAG) por g de extrato bruto e por g de material vegetal seco, são apresentados na Tabela 1. Todos os extratos avaliados apresentaram altos teores de compostos fenólicos, quando comparados a dados de outras espécies descritos na literatura ${ }^{24,25}$. O menor teor de FT foi registrado no extrato $\mathrm{EtOH}$ de raiz de C. prunifera e o maior teor, no extrato EtOH de cascas da T. brasiliensis.

Observou-se uma correlação positiva entre os fenóis totais e a $\mathrm{CE}_{50}$ dos extratos de T. brasiliensis (casca e folha), C. macrophyllum (folha) e $C$. prunifera (raiz), conforme mostrado na Figura 3, no entanto os extratos de $T$. fagifolia e $Q$. grandiflora não seguem este comportamento. Esta análise sugere que existe algum constituinte que contribui particularmente e mais efetivamente para a ação seqüestradora de radicais livres, no extrato destas duas espécies.

Considerando que substâncias naturais podem ser responsáveis pelo efeito de proteção contra os riscos de muitos processos patológicos, os resultados descritos neste trabalho estimulam a continuidade dos estudos para avaliar a ação antioxidante de substâncias isoladas das espécies $T$. brasiliensis (casca e folha), T. fagifolia, $Q$. grandiflora e C. macrophyllum (folha).

Tabela 1. Conteúdo de fenóis totais $(\mathrm{FT})$, atividade antioxidante $\left(\mathrm{CE}_{50}\right)$ e rendimento $(\%)$ do extrato etanólico de cinco plantas medicinais

\begin{tabular}{|c|c|c|c|c|c|}
\hline & ras & Rendimento do & FT (mg de EAG/g de & FT (mg de EAG/g de & $\mathrm{CE}_{50} \pm \mathrm{DP}$ \\
\hline 1. & T. brasiliensis (casca) & 6,0 & $763,63 \pm 13,03$ & $45,82 \pm 0,78$ & $27,59 \pm 0,82$ \\
\hline 2. & T. brasiliensis (folha) & 5,8 & $667,90 \pm 10,92$ & $38,53 \pm 0,63$ & $44,53 \pm 1,09$ \\
\hline 3. & C. macrophyllum (folha) & 13,7 & $483,63 \pm 26,00$ & $66,14 \pm 3,56$ & $78,45 \pm 5,03$ \\
\hline 4. & T. fagifolia (folha) & 22,0 & $439,38 \pm 3,15$ & $97,6 \pm 0,70$ & $42,23 \pm 1,72$ \\
\hline 5. & Q. grandiflora (folha) & 9,8 & $394,90 \pm 3,20$ & $38,70 \pm 0,30$ & $50,16 \pm 0,82$ \\
\hline 6. & C. prunifera (raiz) & 4,6 & $250,00 \pm 8,20$ & $11,55 \pm 0,40$ & $111,14 \pm 12,48$ \\
\hline 7. & Ácido gálico & - & - & - & $24,27 \pm 0,31$ \\
\hline 8. & Rutina & - & - & - & $27,80 \pm 1,38$ \\
\hline
\end{tabular}

$\mathrm{EAG}=$ equivalente de ácido gálico; $\mathrm{CE}_{50}=$ concentração eficiente; $\mathrm{DP}=$ desvio padrão da média 

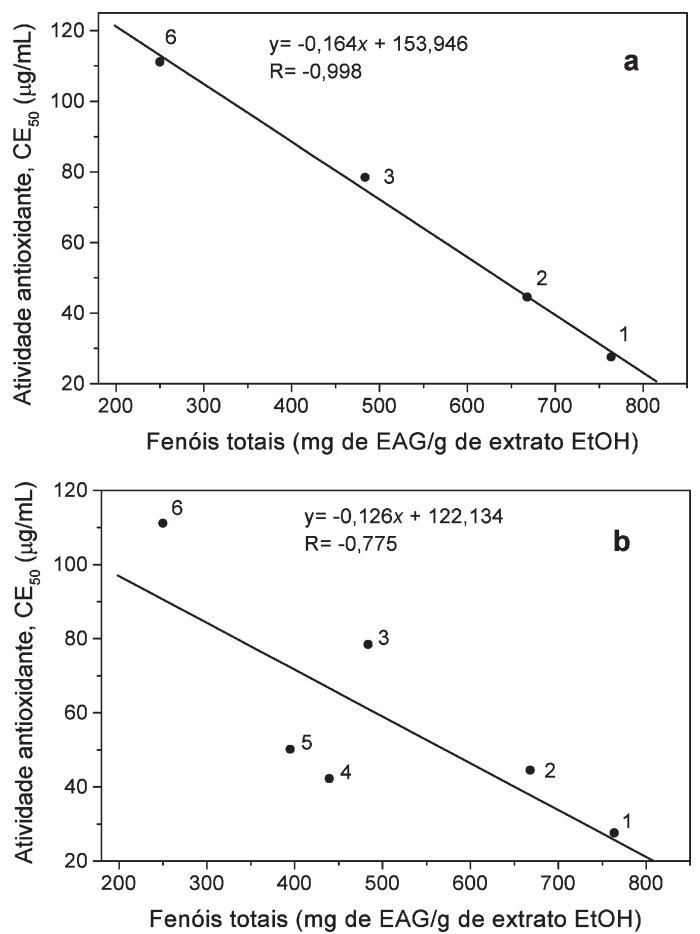

Figura 3. Correlação entre os fenóis totais expressos em equivalente de ácido gálico, EAG e atividade antioxidante, expressa como concentração eficiente, $C E_{50}$ do extrato etanólico. (a) Extratos das espécies 1, 2, 3 e 6. (b) Todos os extratos testados: 1. T. brasiliensis (casca); 2. T. brasiliensis (folha); 3. C. macrophyllum (folha); 4. T. fagifolia (folha); 5. Q. grandiflora (folha); 6. C. prunifera (raiz)

\section{AGRADECIMENTOS}

Aos órgãos financiadores pelo apoio financeiro (CAPES/ PROCAD N ${ }^{\circ}$ 0014/01-0, FINEP e CNPq,) e pelas bolsas concedidas a M. H. Chaves, G. M. Vieira-Jr. e M. C. Ayres (CNPq); C. L. S. Costa, H. R. Silva e D. S. Araújo (CAPES); P. B. M. Araújo (FAPEPI/ CNPq); L. C. Duarte; E. D. S. Barros e M. S. Brandão (UFPI). À Dra. G. M. Sousa do Herbário Graziela Barroso, UFPI, pela coleta e identificação do material botânico. Ao Prof. Dr. José Machado Moita Neto pelas discussões sobre a análise estatística dos dados.

\section{REFERÊNCIAS}

1. Atoui, A. K.; Mansouri, A.; Boskou, G.; Kefalas, P.; Food Chem. 2005, 89, 27; Barreiros, A. L. B. S.; David, J. M.; David, J. P.; Quim. Nova 2006, 29, 113

2. Valko, M.; Izakovic, M.; Mazur, M.; Rhodes, C. J.; Telser, J.; Mol. Cell. Biochem. 2004, 266, 37; El-Agamey, A.; Lowe, G. M.; McGarvey, D. J.; Mortesen, A.; Phillip, D. M.; Truscott, T. M.; Young, A. J.; Arch. Biochem. Biophys. 2004, 430, 37; Omoni, A. O.; Aluko, R. E.; Trends Food Sci. Technol. 2005, 16, 344.

3. Haslam, E.; J. Nat. Prod. 1996, 59, 205.

4. Naczk, M.; Shahidi, F.; J. Chromatogr., A 2004, 1054, 95

5. Soares, S. E.; Rev. Nutr. 2002, 15, 71.

6. Chun, S.-S.; Vatem, D. A.; Lin, Y.-T.; Shetty, K.; Process Biochem. 2005, 40, 809.

7. Bonoli, M.; Verardo, V.; Marconi, E.; Caboni, M. F.; J. Agric. Food Chem. 2004, 52, 5195.

8. Rababah, T. M.; Hettiarachchy, N. S.; Horax, R.; J. Agric. Food Chem. 2004, 52,5183 .

9. Hou, W.-C.; Lin, R.-D.; Cheng, K.-T.; Hung, Y.-T.; Cho, C.-H.; Chen, C.H.; Hwang, S.-Y.; Lee, M. H.; Phytomedicine 2003, 10, 170.

10. Roginsky, V.; Lissi, E. A.; Food Chem. 2005, 92, 235.

11. Ikawa, M.; Schaper, T. D.; Dollard, C. A.; Sasner, J. J.; J. Agric. Food Chem. 2003, 51, 1811.

12. Brand-Williams, W.; Cuvelier, M. E.; Berset, C.; Lebensm.- Wiss. Technol. 1995, 28, 25.

13. Sánchez-Moreno, C.; Larrauri, J. A.; Saura-Calixto, F.; J. Sci. Food. Agric. 1998, 76, 270.

14. Corrêa, M. P.; Dicionário de Plantas Úteis do Brasil, Imprensa Nacional: Rio de Janeiro, 1974, vol. 5.

15. Araújo, D. S.; Chaves, M. H.; Quim. Nova 2005, 28, 996.

16. Araújo, D. S.; Dissertação de Mestrado, Universidade Federal do Piauí, Brasil, 2005.

17. Almeida, S. P.; Proença, C. E. B.; Sano, S. M.; Ribeiro, J. F.; Cerrado espécies vegetais úteis, Embrapa: Planatina, 1998.

18. Santos, F. J. B.; Dissertação de Mestrado, Universidade Federal do Piauí, Brasil, 2001; Costa, A. F.; Dissertação de Mestrado, Universidade Federal do Piauí, Brasil, 2003; Costa, C. L. S.; Dissertação de Mestrado, Universidade Federal do Piauí, Brasil, 2005.

19. http://www.machado.com.br acessada em Junho 2005; http:// www.pvp.com.br, acessada em Junho 2005.

20. Carvalho, J. B. M.; Ensaios sobre a carnaubeira, Ministério da Agricultura: Rio de Janeiro, 1957

21. Soler-Rivas, C.; Espín, J. C.; Wichers, H. J.; Phytochem. Anal. 2000, 11, 1.

22. Yen, G.; Duh, P. D.; J. Agric. Food Chem. 1994, 42, 629.

23. Moreira, D. L.; Leitão, S. G.; Gonçalves, J. L. S.; Wigg, M. D.; Leitão, G. G.; Quim. Nova 2005, 28, 421.

24. Velioglu, Y. S.; Mazza, G.; Gao, L.; Oomah, B. D.; J. Agric. Food Chem. 1998, 46, 4113.

25. Kähkönen, M. P.; Hopia, A. I.; Vuorela, H. J.; Rauha, J.-P.; Pihlaja, K.; Kujala, T. S.; Heinonem, M.; J. Agric. Food Chem. 1999, 47, 3954. 